\title{
AC 2007-2256: ATTRACTING AND RETAINING FEMALES IN ENGINEERING PROGRAMS: USING AN STSE APPROACH
}

\section{Lisa Romkey, University of Toronto}

Lisa Romkey is the Lecturer, Curriculum, Teaching and Learning with the Division of Engineering Science at the University of Toronto. In this position, Lisa plays a central role in the continuous improvement of the design and delivery of a dynamic and complex curriculum, while facilitating the development and implementation of teaching and learning initiatives and innovations. Lisa is cross-appointed with the Department of Curriculum, Teaching and Learning at OISE/UT (Ontario Institute for Studies in Education at the University of Toronto). Lisa holds a Masters in Curriculum Studies and is currently pursuing a PhD in higher education at OISE/UT. Research interests include teaching \& learning in higher education, engineering education, first year experience, STSE in higher education and gender issues in science and engineering. 
Attracting and Retaining Females in Engineering Programs: Using a Science, Technology, Society and the Environment (STSE) Approach 


\section{Attracting and Retaining Females in Engineering Programs: Using a Science, Technology, Society and the Environment (STSE) Approach}

There are great strides to be made in the recruitment of women to engineering programs and careers. While women typically make up more than $50 \%$ of individuals studying life science at most universities and colleges across North America, we still see far fewer females in engineering than we do males.

Much of the literature on gender studies in science, technology and engineering suggests females enjoy and connect with these fields when subjects are placed within a human, social or environmental context. STSE (Science, Technology, Society and the Environment) education is based on the idea that science education should include a variety of perspectives on science; historical, philosophical, cultural, sociological, political and ethical. The STSE educational approach typically includes the following features:

- An understanding of the environmental threats, including those of a global nature, to our quality of life

- The economic and industrial aspects of technology

- An understanding of the fallible nature of science

- Discussion of personal opinion and values, as well as democratic action

- The multi-cultural dimension of science

This paper, through an extensive literature review and qualitative data from interviews with several female engineering students and recent graduates, demonstrates why female students respond well to this form of education, drawing from theories on traditional forms of gender roles, gender socialization and moral development. The interviews explore initial perceptions of, and experiences with, science and engineering and the importance of contextualized learning, as well as future aspirations, in the engineering field. 
Introduction

There are great strides to be made in the recruitment of women to engineering programs and careers. While women typically make up more than $50 \%$ of individuals studying life science at most universities and colleges across North America, we see far fewer women in engineering programs than we do males. There is a considerable body of research that suggests ways to improve this, including mentorship programs, a change in the nature of the engineering workplace to accommodate family needs, and creating a more collaborative and less competitive atmosphere in both the academic and industry sides of engineering.

Much of the literature on gender studies in science, technology and engineering suggests females enjoy and connect with these fields when they are placed within a human, social or environmental context. This paper demonstrates the why and how of this relationship, drawing ideas from gender roles and gender socialization. This paper looks at how moral development may impact a woman's choice to pursue a career in the physical sciences, technology, engineering or math. In particular, the paper draws from Gilligan's theories on females and the care-orientation of moral development, and how her theories demonstrate a need for a STSE (Science, Technology, Society and the Environment) orientation in high school, college and university curriculum.

The extensive literature review in this paper is supplemented by qualitative data from 10 semi-structured interviews with female engineering students and recent female engineering graduates from a large engineering school in Canada. The subjects were interviewed individually, and came from a diverse set of academic and cultural backgrounds, engineering disciplines, interests and aspirations. The interviews were conducted in-person or via telephone, and were 30-45 minutes in duration. The interviews were structured around the following list of questions, however, the individuals interviewed were encouraged to share any thoughts on their experience, and some themes developed, and were encouraged, on an individual basis.

- Why did you decide to pursue engineering? Do you feel that females have different reasons than males for pursuing engineering?

- What were your first experiences with science and engineering as a youth? Which sciences were you most exposed to?

- What were your most positive experiences in science and engineering prior to starting university?

- Did you have any hesitation about pursuing engineering as a female?

- What have been your most positive experiences, academically, as an engineering student?

- What do you plan to do with your engineering degree? Do you think females have different goals than males?

- Female numbers in engineering remain relatively low, and have recently been on the decline in Canada. Why do you think this is the case? How can we attract more women to the field of engineering?

- Do you think there are stereotypes about engineering, or about women, that detract women from pursuing engineering?

- Do you think the experience as a student is different for males and females?

- If you could change something about your education as an engineer, what would it be? 
Transcripts from the 10 interviews were reviewed and coded to identify a number of themes, upon which themes across interviews were compared to identify trends. Throughout the paper, embedded in the literature review, 8 common trends that emerged from the qualitative interview data are identified and explored.

Women and STEM

\section{A Brief History and Current Statistics}

While women have made great strides in the fields of science, technology, engineering, and mathematics (STEM), inequalities remain. As long as the inequalities exist at both the academic and career levels, we will continue to miss the unique perspectives women can bring to the design of new technologies and scientific procedures.

Females have traditionally been excluded from science and math, and this exclusion dates back to $600 \mathrm{BC}$, as Pythagoras and his followers established mathematics as a religious activity in which only men were said to have the abilities to partake ( $\left.\operatorname{Simon}^{52}, 2000\right)$. During the renaissance period, the popular view was that women's brains were too cold and too soft for the rigorous theory behind math and science. Women's education through the $18^{\text {th }}$ and $19^{\text {th }}$ centuries focused on issues relating to the home and motherhood, and only limited and undefined connections to science were provided through biology. The domain of the physical sciences and engineering belonged to the boys $\left(\right.$ Tolley $\left.^{63}, 2003\right)$.

To include women in the history of science requires a shift in how we look at science and women's involvement, for example how sciences and engineering relate to domestic life in the $18^{\text {th }}$ and early $19^{\text {th }}$ centuries (Kohlstedt $\left.{ }^{35}, 1999\right)$. In fact, the study of botany was framed for and by women in the late $18^{\text {th }}$ century, who used their knowledge in gardening, herbal medicine and food preparation. Women living in rural areas, through organizations such as the Women's Institute in Ontario, shared knowledge about science relating to the home such as farm work, health, food and hygiene issues. This would give birth to schools such as the MacDonald Institute at the University of Guelph (McPhedran $\left.{ }^{40}, 2003\right)$.

Engineering was a men's club until the late 1800's, at which time very few women took up the discipline. In 1893, only three women had ever received an engineering degree in the United States (Lebold and Lebold ${ }^{38}$, 1998).Ironically, while women led anti-war efforts during WWI and WWII, war also brought opportunity for women to pursue engineering, as a shortage led to the training of women to "fill the gaps". Even at this time, women faced discrimination, exclusion from professional societies and job loss in economic downturn.

Linked to this "men's club" atmosphere emerges the first theme taken the interviews. The young women interviewed gave indications that a "men's club" atmosphere is still evident, and that not all behaviour exhibited in their undergraduate engineering program would be considered "female-friendly":

"If I was a guy, and I had a younger sister that wanted to go into engineering, I wouldn't encourage her. Do I want my little sister to walk by the cafeteria and see a bunch of naked guys? Not really. I think there are certain traditions...some have died away, but a lot haven't. It's going to make girls feel uncomfortable..." 
"In first year, the first thing I was told at a tutorial by (a fellow student) was that I was here because the university wanted more women."

"Sometimes (the male students) will joke, "show a little leg at your interview”...but I don't think they really mean it..."

"I think that with males specifically in engineering, a lot of your, I guess, your respect or bragging rights are from your endurance, your ability to do things... are you the best at chugging beer... and social activities are based on that."

"Outside of the classroom, in social atmospheres, you're always going to hear all the guys talk about how crazy girls are, and they don't understand girls, and you just kind of have to sit there and go with it and listen to it."

While the number of women pursuing higher education around the globe has increased dramatically in recent decades, the greatest increases have been seen in life sciences, arts, humanities and business (Ramirez and Wotipka ${ }^{44}, 2001$ ). The percentage of women in Canadian engineering undergraduate programs increased from $3.6 \%$ in 1975 to over $20 \%$ in 2000 , but it has now plateaued at $17.5 \%$. In 2005, females made up less than $18 \%$ of the graduate student enrollment in engineering programs in Canada

Some of these figures are disproportionately skewed by the biological science-oriented undergraduate engineering programs, which have higher numbers of female students, such as chemical, biological and environmental engineering. Other engineering programs, such as electrical and mechanical engineering, had $14 \%$ and $11 \%$ female populations respectively in Canada in $2005\left(\mathrm{CCPE}^{11}, 2005\right)$.

Women also comprise a much lower proportion of the engineering faculty composition of North American colleges and universities. We continue to face issues in recruiting females to related academic programs and careers, despite a growing number of women obtaining doctoral degrees in engineering (Cordova-Wenthing and Camacho ${ }^{12}$, 2006). Women also appear to face difficulties in advancing in careers in academia; they are typically making less money, are less likely to apply for research grants and are more likely to be on short-term contracts with their institution (Bebbington ${ }^{6}, 2002$ ). The fall-out of this alarming trend is that females, if they do reach a science or engineering program in university, are faced with a lack of female role models to relate to upon arrival.

\section{Where are the Females?}

Some researchers believe that the exclusion of women from the sciences has resulted in a masculine construction of science (Tolley ${ }^{63}, 2003$ ), which may explain the "traditional" engineering education characteristics and the reasons why females are not pursuing study in these areas. Females' lack of interest in physical science begins at a young age, with elementary school females typically choosing science fair projects related to biological sciences and males choosing projects relating to a broader spectrum of science and engineering-related topics (Brickhouse, Lowery and Schultz $\left.{ }^{8}, 1999\right)$. Females typically take fewer math courses than do males, therefore limiting options in math, science and engineering programs (Eisenberg, Martin and Fabes ${ }^{19}$, 1996). Generally, males tend to rate math and science as being more important and useful than do female students (Stage et $\mathrm{al}^{56}$, 1985). While the number of females taking these courses is on the rise, women typically have 
less definite ideas about careers in math and science than their male counterparts once entering university (Thom ${ }^{62}$, 2002).A major research project funded by the Scottish Higher Education Funding Council found that not only are the number of women entering and finishing programs in science and engineering low, but the number of women with the appropriate academic background who actually pursue related careers is even lower (Cronin and $\operatorname{Roger}^{13}$, 1998).

Past ideas pertaining to innate, biological differences between males and females are becoming more and more insignificant, and the differences that are found between the sexes are typically small and often inconsistent (Stage et $\left.\mathrm{al}^{56}, 1985\right)$. While some research demonstrates that females outperform males at computation, but males excel at reasoning and complex applications (Linn and Hyde ${ }^{39}$, 1997), these differences in research seem to be declining. Some researchers believe that women's peculiarities in the right hemisphere of the brain make them unable to visualize spatial relationships, while others dispute this idea $\left(\right.$ Simon $\left.^{52}, 2000\right)$.Spatial ability has long been a contentious issue when examining differences between males and females, but some research, including one particular study conducted by Linn and Hyde ${ }^{39}$ (1997) demonstrated that differences only occur in some instances, and these differences can be eliminated with training.

However, some research does indicate that while males and females have similar math and science proficiency scores around the age of 9 or 10, gaps begin to appear at age 13, where males begin to score higher (Byrnes and Takahira ${ }^{9}, 1993$, The Condition of Education $1997^{60}$, 1998). Studies indicate both a growing difference in proficiency scores as the students moved into secondary school, as well as fewer aspirations to become scientists or engineers and a growing disparity between the number of men and women taking optional science and math courses. These disparities may be linked to confidence: while the innate, biological differences between men and women and how they can affect ability in science and math are highly contentious, the confidence levels of most females versus males is certainly not. Several researchers have demonstrated a marked difference in confidence levels between males and females (Stage et $\mathrm{al}^{56}, 1985$, The Condition of Education $1997^{60}, 1998$ ). Reis and $\operatorname{Park}^{45}$ (2001) found that males are more likely to acknowledge their success in science and math, but blame failure on lack of effort, where females are less likely to acknowledge success and if they do, they often attribute it to luck. Seymour ${ }^{51}$ (1995) found similar attitudes in young people, and suggested that the most marked difference between males and females lies in their self-confidence. Researchers have also found that girls react more negatively to bad grades, potentially causing further damage to their math \& science selfesteem. Bevan ${ }^{7}$ (2001), when looking specifically at mathematics found that the difference in attitude between males and females is surprisingly great - boys expressed a much higher expectation of success, and girls continued to express uncertainty in their abilities, even after scoring high on a test. Karp and Shakeshaft ${ }^{32}$ (1997) found that males dominate classroom conversation and are generally more confident in the classroom setting. This issue of confidence is a serious one, as confidence is often found to be precursor to achievement.

The second theme that emerged from the interview results reflects issues of confidence and program choice. The interview subjects made interesting comments about why females are choosing not to pursue engineering:

"I was really worried about it in high school. I was good in english...I had good marks in math and science, but I was never super outstanding. There's the fear that you're not good 
enough, even though you have the same marks as someone else - males - who think they're more than good enough. You feel you need to be extra good as a female."

"I think a lot of people are still intimidated by it. Some of my high school friends wouldn't consider engineering, they thought it would be too difficult. So they decided to go into life science."

"You hear engineering, and you automatically think math and science. In a lot of girls, that invokes fear."

Some researchers believe that the gender differences in science and math can be attributed not only to the confidence issue, but also to females' lack of experience outside of the classroom and the gender bias of family, teachers and peers (Dimitrov $\left.{ }^{16}, 1999\right)$. One study by Desouza and Czerniak ${ }^{15}$, 2002) observed pre-school children while they were engaged in science activities. They found that while boys acted in ways that were more active and aggressive, girls expressed a greater degree of uncertainty and fear, asking for more help than their male counterparts. The researchers also found that the boys had more to talk about in regards to prior experience with science, and so the researchers concluded that pre-school females need to be exposed to more science, both within and outside of an educational setting.

Women who study science or engineering are often drawn to it through active and cooperative learning, group work, counseling, field trips, discussions, and ideas that bring the curriculum to the wider context of social and environmental issues (Thom ${ }^{61}$, 2001). A lack of appropriate curriculum and teaching tactics at all levels of education may be to blame for the lack of female participants, but it also presents an opportunity to improve our efforts in recruiting women to related fields. Why is it that women need different teaching methods and a context-rich curriculum? The next section of the paper discusses how gender roles and gender socialization may affect the educational needs of our female students.

Identity \& Gender Development

The ways in which males and females develop a self-concept and personal identity, which has great influence on chosen career paths and academic interests, has been demonstrated as being different. For example, women tend to place an increased emphasis on connectedness and relationships in their development of identity and autonomy (Jones and Watt ${ }^{31}, 2001$ ). The process of identity development is individual, but is also situated in society, which holds particular norms and values (Brickhouse, Lowery and Schultz $\left.{ }^{8}, 1999\right)$. This can lead to males and females acting in particular ways - such as choosing a particular career path that is confined to the norms of their gender in society.

The female identity was the third theme identified in the interview data. The female engineers interviewed identified some of the challenges in choosing and pursuing engineering, given their identity and concerns as a female:

"It's known as a manly thing to do, not something that women would want to study. I think that hurts at the high school level. There is a perception that engineers are grease monkeys, and that it's not a very feminine thing to do." 
"If you are a female going into engineering, it means you think, act and even look like a boy. You don't act like a girl, you fit in with the boys."

"We are attracted to caring professions...it's just our nature. You look back at history. We are the wife/mother role. We are generally more nurturing of the genders."

"I found that being a girl in engineering...just because of the way the numbers are...your friends are predominately male. So you kind of have to give up your girliness, a lot of the time, just to fit in with the group."

Children begin to label themselves as a male or female as early as age two (Golombok and Fivush $^{23}$, 1994). Child development theorist Kohlberg suggested that between the ages of four and seven, children develop gender constancy, or a recognition of the behaviors, toys and activities that make them male or female (O'Keefe and Hyde ${ }^{41}$, 1983). These pieces of information that dictate gender are called "Gender schemas", or organized knowledge structures that contain information about the sexes. These gender schemas guide behaviour and decision-making in children as they develop their personal identity (Eisenberg, Martin and Fabes $\left.{ }^{19}, 1996\right)$. A child's sense of self comes from the ideas, attitudes, behaviours and beliefs that they are exposed to in relation to their gender (Brickhouse, Lowery and Schultz ${ }^{8}$, 1999). During childhood, there is a preference for interacting with same-gender peers, and learners acquire information from this environment and add to prior experiences to form a gender-based identity (Desouza and Czerniak ${ }^{15}, 2002$ ).

Occupational stereotyping appears early in children, and research has demonstrated that at the age of 3-6, children are more likely to show interest in gender-stereotypical jobs. Similar results occurred at the 8-10 age range (O'Keefe and Hyde $\left.{ }^{41}, 1983\right)$. Ideas about occupational stereotyping grow stronger as children grow older, and this certainly has an effect on a child or teenager's perception of women in engineering.

Gender Stereotypes and Gender Roles

One's idea of their "gender role" is developed through the influence of a number of sources, all of which reinforce each other; parents, peers, media and school (Campbell and Beaudry ${ }^{10}$, 1998). While individually, these sources may be considered insignificant, when brought together, one realizes the significance of the various forces acting on a child's life experience. Information about gender roles include various gender stereotypes, which can be defined as organized knowledge structures that label gender-related attributes (Eisenberg, Martin and Fabes $\left.^{19}, 1996\right)$. Gender stereotypes may include information about physical appearance, attitudes and interests, psychological traits, social relations and occupations (Golombok and Fivush $^{23}$, 1994).

The fourth theme identified by the female engineers interviewed were issues surrounding stereotypes, and the reactions from others on their decision to enter engineering. In fact, nearly every female mentioned that people were surprised to hear about their decision:

"I got asked a lot, why are you here? What are you doing here? What prompted you to go into engineering?"

"I know when I was at School, and at a party, with a variety of students from different programs, I would get a weird look when I said I was in engineering. I would get a double 
take - "OH, OK, that's cool...why are you going into that". One of my guy friends would answer the same question and get a totally different response - no one thought twice about it. It's still rare, as long as it is, people will still do the double take. It was like "Oh...I didn't realize you were smart"."

"When you tell someone you are going into engineering, you don't really get "that's really good for you, you get "Oh."."

"People kept asking me, why are you going into engineering? I had to keep justifying it over and over again. For the guys that were applying, it was like, oh ya, he's going to be an engineer."

It would be difficult for a female to not feel the effects of a gender stereotype, as ideas about the differences between men and women are so prevalent in our society. While society's rules and norms may be different within different cultures, there is a surprising degree of similarity in gender stereotypes across different cultural groups (Golombok and Fivush ${ }^{23}$, 1994). Infants are surrounded by cues signifying gender, and are given gender labels based on things such as body parts and toys.

Ideas about males and females and their gender roles are perpetuated by the reinforcement from these different sources, such as the idea that males are the dominant members of society (Tater and Emmanuel ${ }^{58}$, 2001). As children develop, they absorb new information and place it in the context of what they already know (Witt $\left.{ }^{70}, 2000\right)$. This means that if a child first believes that all scientists are male, they will often hold onto this gender-based idea unless faced with an intervention. Children use their stereotypical knowledge to make further stereotypes, and will often believe that all of one gender has the same characteristics and that others of the same gender will enjoy the same activities that they do (Eisenberg, Martin and Fabes $\left.{ }^{19}, 1996\right)$. As a result of gender role knowledge, children will go as far as to deny the reality of a boy or girl if it does not fit a pre-conceived notion or understanding of what a boy or girl should be (Witt $\left.{ }^{68}, 1997\right)$. Specifically, by age 4-7, children will disregard any information about another child in favor of matching them up to a particular gender through stereotypical information. As they get older, they recognize that not all girls and boys are the same, but will still base many of their predictions about people on traditional stereotypes if they do not have other knowledge to draw from (Golombok and Fivush ${ }^{23}$, 1994).

Knowledge of the causes of gender-stereotypic behaviour and gender differences can be used to promote good psychological health and constructive social behaviour, and we can avoid the trap of limiting children's potential by making assumptions about what males and females can and cannot do (Eisenberg, Martin and Fabes $\left.{ }^{19}, 1996\right)$. The following provides a closer examination of the four main sources of gender role creation and perpetuation:

\section{Parents}

Gender roles are first learned in the home, and are then reinforced by peers, school and the media. Parents act as role models, approving or disapproving, sharing their own values and ideas with their children (Witt ${ }^{69}, 2000$ ). Both research and common knowledge demonstrates that parents treat sons and daughters differently - in how they are dressed, their activities, toys and behavior expectations (Witt $\left.{ }^{68}, 1997\right)$. Parents assign chores based on gender, and in fact, some research suggests that those children who engage in cross-stereotypical chores are actually more likely to choose non-traditional careers (Eisenberg, Martin and Fabes ${ }^{19}, 1996$ ). 
Even in instances where females achieve higher marks than males, parents still tend to believe that males are innately better in mathematics (Reis and Park ${ }^{45}, 2001$ ) and often provide greater encouragement related to entering a degree in math, science or engineering to a son than a daughter (Atkin, Green and McLaughlin ${ }^{4}, 2002$, Hoffmann ${ }^{28}, 2002$ ). This is highly significant, as parental expectations and attitudes towards children have a very strong impact on a child's self-confidence (Witt ${ }^{69}, 2000$, Eccles and Jacobs ${ }^{18}, 1986$ ). In fact, parental beliefs about their children's abilities has been found to have a greater influence than does previous performance (Eisenberg, Martin and Fabes ${ }^{19}$, 1996) and the mother's opinion seems to have a particularly strong influence on students' confidence. Often times, it is actually media reports about sex differences in math that have a negative impact on the confidence mothers have in their daughters' mathematical abilities (Eccles and Jacobs ${ }^{18}, 1986$ ).

Parents can have an enormous role in their child's courage to move beyond gender expectations, though demonstrating a willingness to engage in non-traditional activities (Witt $\left.{ }^{68}, 1997\right)$.

\section{School}

The behavior of teachers and school administrators is often subconscious, based on their own gender socialization as a child, adolescent and adult. While school is a wonderful place for students to examine new opportunities, ideas about gender can affect the behaviour of teachers towards males or females. In fact, stereotypes in the school can influence confidence and academic performance of a student, and are thought to contribute heavily to females' difficulty in school (Reis and Park $\left.{ }^{45}, 2001\right)$.

Numerous studies have demonstrated that boys are more likely to monopolize student-teacher interaction time in the classroom, through their higher level of confidence and participation (Eisenberg, Martin and Fabes ${ }^{19}$, 1996, Jacobs ${ }^{30}$, 1992, Reis and Park ${ }^{45}$, 2001), and that many teachers provide more praise, feedback, attention and support to male students (Seymour ${ }^{51}$, 1995 and Tatar and Emmanuel $\left.{ }^{58}, 2001\right)$. This is not limited to the K-12 system but can also be found in University Classrooms (Reis and Park ${ }^{45}$, 2001). Boys are often seen as having the highest potential and are considered to be more proficient in solving abstract problems, and in fact, research has demonstrated that teachers are less likely to nominate girls who were likely to do well on math testing than they are to name boys who they feel would do well (Reis and $\left.\operatorname{Park}^{45}, 2001\right)$.

The assumptions that are made in the school about boys and girls interests take an effect on the choice of teaching tactics and curriculum materials (Bevan $\left.{ }^{7}, 2001\right)$. Simon ${ }^{52}$ (2000) even suggested that teachers give subtle, often unintentional preference towards encouraging boys in math and science, and Seymour ${ }^{51}$ (1995) also suggested that teachers have lowered expectations for girls. Gender biases can also be found in textbooks and other school-based materials (Eisenberg, Martin and Fabes ${ }^{19}$, 1996), where males and females are often portrayed differently, and females are portrayed less.

A fifth and very common theme mentioned by the interview subjects was the role of the parents and teachers in encouraging females to pursue engineering. Similar to results from a study conducted by Cordova-Wenthing and Camacho ${ }^{12}$ (2006), the subjects cited the importance of parental support and the positive effects of an engineer in the family, as well as issues with teacher and counsellor support. 
"My math and science teachers were always important role models in my life. My parents wanted me to go into business or something like that. I actually never asked them why. They only really pushed my brother. They told me to go for something easier. But I was one of those kids that thought "I want to do it, I really didn't care"."

"Most of female classmates - about $75 \%$ of them - had a parent or sibling who was in engineering, where that was very different for male classmates...it was more common for female students."

"I do think teachers can have that influence, if they aren't getting any reinforcement at home that's leading them in a different way. If my mom hadn't encouraged me to pursue engineering, I probably would have dropped it. I would have gone into science or something."

"My grade 11 and 12 chemistry teacher is a chemical engineer, so she provided a lot of information about engineering. She talked a lot about her undergrad experience. She was a positive role model for me."

"I think that one of the reasons why I chose math and science and chose engineering was because I had a teacher that was female. So if there was more females in engineering that could teach, it would make a big difference."

"I think there is probably a family issue. Parents don't want their girls go to into engineering because they don't think they could do well. My parents thought different."

"If you can get parents to think that their daughters should become engineers - like, a lot of parents think their daughters should be doctors - if you can get that for engineers, I think more girls would go into engineering. I think the trick is to tackle the parents."

Peers

Gender role socialization from peers is based on various interactions, popularity and rejection, friends and enemies. Children make a determination of themselves and their capabilities based on their perception of what others think of them, and often this shapes their idea of what they need to do to fit into society. Girls are often shunned for acting aggressively or being assertive, where boys get negative feedback for acting in ways that are considered "feminine" (Witt" $\left.{ }^{70}, 2000\right)$.

Peers and peer groups play a significant role in a child's idea of what males and females should be and do. Children play primarily in same-sex groups, and peer reinforcement and punishment constantly influence children's activity and toy preference. Where boys in peer groups often spend time doing activities that are active, aggressive and unstructured, girl groups tend to engage in activities that are sedentary, highly structured and nurturing (Eisenberg, Martin and Fabes ${ }^{19}$, 1996). In peer groups, boys seek to establish status where girls seek to cultivate close friendships (Witt ${ }^{69}, 2000$ ). The activities a child engages in with a peer group may have an effect on personal expectations and career aspirations.

Media 
In the media, males are often portrayed as rational, competitive, powerful and smart, where females are more often presented as sensitive, happy, warm and timid. The lives of most children are inundated with media images, as preschoolers spend an average of 30 hours each week watching television, and start at this very young age to internalize gender role stereotypes they find in the media $\left(\mathrm{Witt}^{70}, 2000\right)$. Males and females are found to be depicted very differently across various mediums. Males are often featured more than females, and female characters fit certain social stereotypes such as working in the home, or on commercials related to stereotypical products (Golombok and Fivush ${ }^{23}, 1994$ ).

Gender role stereotypes are not limited to the television, and can also be found in books, songs, movies and music. A study on children's books by Taylor ${ }^{59}$ (2003) found that while boys were portrayed as active and outdoors-oriented individuals, often in leadership roles, females were portrayed as passive followers who preferred to stay indoors. These gender role stereotypes are highly prevalent and children will typically imitate and repeat behaviour they see in the media, recognizing that acceptance into society means conforming to a traditional gender-based role. Other research on storybooks has found that males are represented more, and if the gender is "in question", children will assume the individual is male (Golombok and Fivush $^{23}$, 1994).

We include toys as another source of gender-stereotyping. Research by Robinson and Morris $^{46}$ (1986) found that sex-typed toys (such as vehicles, puzzles, sports equipment for boys, and dolls, domestic items for girls) were largely in a child's room by request, as opposed to chosen by parents (who are more likely to choose gender-neutral toys, such as art supplies). While some researchers feel that the media leads children to request sex-typed toys, others predict that parents and teachers unknowingly encourage children to play with gender-stereotyped toys.

Another media issue is the portrayal of engineering as a male-dominated field (CordovaWenthing and Camacho ${ }^{12}$, 2006). Interestingly, another theme that was common between the interview subjects was the mention of a lack of positive or popular media attention around engineering. This is indicative of the interviewees' understanding of the major influence of mainstream media on life choices:

"I think we don't have a lot of females because there's no engineering TV shows...that is a big thing. And I find that it's so true! We're not a high profile profession, compared to some of the other ones that are getting attraction from young females, like the whole forensics, hospitals, being a therapist - you get that exposure on TV."

"Make a hit TV show. Star some really good looking people, and have them be engineers, so that it's kind of out in the public what it is and what they do and they can see that yes I can do that, yes it's really cool."

\section{"I think a TV show (about engineering) would be a good idea!"}

While we must take caution in designing a curriculum in response to gender stereotypes, it is an interesting way to look at what people aspire to be and how it affects their choice of career and academic program. While some individuals may have the encouragement to go beyond gender stereotypes, we must recognize that many females are trapped by society's expectations of their roles. If educators have the confidence to make changes to the way the physical sciences, engineering and mathematics is taught, potentially through an STSE 
approach, there is great opportunity to change the nature of these disciplines and give greater encouragement to females.

The Female's Moral Development and Moral Reasoning

One's sense of moral development affects not only how they decide between right and wrong, but will also affect how they choose an academic and career path, while striving towards something meaningful.

The initial ideas on moral development, most notably those developed by Freud, Kohlberg and Erikson, were developed from research conducted solely with males. Kohlberg's theory of moral development, based on an initial investigation with 50 males (both Freud and Erikson used male subjects as well), has been acknowledged and used by psychologists, researchers and educators for years (Langford ${ }^{36}, 1995$, West and Bursor ${ }^{66}, 1984$ ). Kohlberg's theory of moral development was based on a justice perspective - enclosing ideas such as individual rights, autonomy, detachment and separation (Jones and Watt ${ }^{31}, 2001$ ). These words could also describe a traditional way of looking at science, through the eyes of science education, as isolated and disconnected concepts, and this is where a parallel is drawn between one's moral development and their response to science, engineering and mathematics. Traditional science is masculine, competitive, objective and impersonal, often creating a sense of alienation among female students (Brickhouse, Lowery and Schultz ${ }^{8}$, 1999) while catering to males.

Kohlberg's model of moral development is based on stages that progress from reliance on relationships to independence $\left(\right.$ Hekman $^{25}$, 1995). Kohlberg's sequence of moral development was proposed as follows (Langford $\left.{ }^{36}, 1995\right)$ :

1. Heteronomous morality: the avoidance of breaking rules to avoid punishment and the general avoidance of physical damage to persons or property

2. Individualism, instrumental purpose and exchange: following rules to meet one's own interests and letting others do the same

3. Mutual interpersonal expectations, relationships and interpersonal conformity: living up to what others expect, and generally being a good person, through characteristics such as trustworthiness, loyalty and respectfulness

4. Social system and conscience: fulfilling duties to which an individual has agreed to fulfill, such as upholding the law, or contributing to a group or society

5. Social contract or utility and individual rights: the values and rules one holds are relative to one's own group and may not be held by others. However, as a member of society there are rules to obey, obligations to fulfill and fundamental rights to uphold

6. Universal ethical principles: having self-chosen ethical principles, which are universal perspectives of justice and equality in human rights and respect for humans

Kohlberg suggested that females might be less developed in the sequence than others, often not completing stages 4, 5 and 6. He suggested that females lag behind males because they are not given the same opportunities or expectations in society (Langford $\left.{ }^{36}, 1995\right)$, which highlights some of our understanding about gender roles, stereotypes and socialization and how these things affect confidence and career choice.

Gilligan's 22 (1982) groundbreaking work, outlined in "In a Different Voice" describes the female's own way in approaching morality, one that is not inferior nor superior to a male's moral reasoning. Gilligan, a former graduate student of Kohlberg, felt that the models 
developed by Freud, Erikson and Kohlberg were founded on the experiences of male children and did not properly consider female development. She theorized that females and males, due to differences in socialization, develop two different approaches to morality. She believes the female's moral development centers around an ethic of care, focusing on the particulars of relationships, as opposed to a male's moral development, which focuses on an ethic of justice and rights, focusing on the needs of groups, individuals, policy and the law (as described by Kohlberg). While an ethic of justice certainly includes the consideration of individual and relational needs, Gilligan has proposed that this is a much stronger component in the female ethic.

Gilligan felt that females followed a sequence different than that of Kohlberg's moral development model. In contrast to Kohlberg's model, Gilligan's model of moral development for females does not move to a state of independence, but is represented by changes in a female's relationship role (Hekman ${ }^{25}$, 1995). Gilligan's theory on female moral development begins with a preconventional stage, where decisions are based on consequences which may include reward or punishment for certain behaviour. The second stage, conventional, is represented by an ability to care for and protect others, leading to a restriction on selfexpression. The final stage, postconventional, has the female acknowledging personal desires as well as a consideration of others - in other words, making compromises and accepting responsibility of choices (Gilligan $\left.{ }^{22}, 1982\right)$. Essentially, the woman's moral dilemma is finding the right balance between self, others and relationships in her life (Golombok and Fivush $^{23}$, 1994).

Gilligan believed that while males are more likely to prefer autonomy, separation, certainty and control, females are often connected to the world through relationships and empathy. ${ }^{31}$ Gilligan's idea of female moral reasoning based on an ethic of care views individuals as connected with others and stresses the importance of relationships, being sensitive to others needs and the avoidance of harm caused to other people (Jones and Watt ${ }^{31}, 2001$ ). Gilligan ${ }^{22}$ (1982) postulates that a women's sensitivity to the needs of others and their sense of responsibility for the care of others leads them to attend to others and include other points of view when making decisions, and that their moral dilemma comes from these conflicting responsibilities and conflicting "voices of others". Gilligan based her theory on Chodorow's formulation of female development: specifically, on the premise that females never fully separate from their mother in order to form their gender identity, and the idea that females define themselves in terms of their relationship to others (Golombok and Fivush ${ }^{23}, 1994$ ). Also, mothers tend to talk more about their emotions with their daughters, potentially conveying the message that females should be more concerned with human emotions and relationships (Eisenberg, Martin and Fabes ${ }^{19}$ (1996). While Gilligan was praised for bringing forward this new theory, she has also been criticized for her methodology and the fact that by some, she is considered an antifeminist for presenting differences between males and females $\left(\right.$ Hekman $\left.^{25}, 1995\right)$. Her research methods have been faulted for not having a large enough sample size, and for focusing solely on young women (Kohlberg, Levine and Hewer ${ }^{34}, 1983$ ).

While some researchers have reported no significant differences between males and females on moral development, other research has suggested that a difference does indeed exist, and that females are more likely to use an ethic of care perspective and males are more likely to use a justice perspective (Kohlberg, Levine and Hewer ${ }^{34}, 1983$ ). A study by Jones and Watt ${ }^{31}$ (2001) looked at 182 male and female undergraduate students, and while they found that both sexes used both moral perspectives (the justice perspective and the care perspective), women were found to possess a significantly higher ethic of care. Recent research has produced 
consistent gender differences in moral reasoning. For example, when asked to give a personal moral dilemma, women more often discuss family issues and interpersonal relationships than do males, and women used more care-based reasoning than did males (Golombok and Fivush $\left.^{23}, 1994\right)$.

Some consider the idea that females are more relational, emotional and concerned with social interactions, while males are categorized as aggressive, instrumental and assertive to be a gender stereotype (Golombok and Fivush ${ }^{23}$, 1994). While it is important that we do consider differences between males and females and cater learning to these differences when possible, we also must be careful not to deviate too much from these views, as women or men who do not hold these stereotypical characteristics may be seen in a negative light.

The significance of proposed theories on female moral development in an educational setting is that particular instructional methodologies and content can be used to encourage females. This includes any teaching tactics and curriculum methodology that presents physics, mathematics and engineering in the context of relationships between individuals and/or society - interactive and cooperative learning, providing a strong sense of context with theoretical material, and holistic learning is encouraged for females (Kenway and Gough ${ }^{33}$, 1998). These ideas are characteristic of Science-Technology-Society-Environment (STSE) instruction. The next section of the paper describes the STSE educational movement.

\section{The STSE Movement}

The content of science, math and engineering education is a highly contentious issue, but it is generally agreed upon that science education should help students develop an understanding of the nature of science (Tsai $\left.{ }^{64}, 1999\right)$. The nature of science, its effects on society and the society's reciprocal effects on science are explored thorough STSE - Science, Technology, Society and the Environment. STSE education is based on the idea that science education should include a variety of perspectives on science - historical, philosophical, cultural, sociological, political and ethical (Pedretti $\left.{ }^{43}, 1999\right)$. STSE education may explore a technological artifact, process, a societal issue related to engineering or an issue within the scientific community, relating to an interaction between engineering and society (Aikenhead ${ }^{1}$, 1994)

The STSE educational approach includes the following features (Soloman $\left.{ }^{54}, 1993\right)$ :

- An understanding of the environmental threats, including those of a global nature, to our quality of life

- The economic and industrial aspects of technology

- An understanding of the fallible nature of science

- Discussion of personal opinion and values, as well as democratic action

- The multi-cultural dimension of science

The progression of an STSE unit can follow through a series of steps, as proposed by Hodson $^{27}$ (2003). The first level of learning is represented by gaining an appreciation of the social impact of scientific and technological change. The second level includes students making decisions about scientific and technological developments, weighing the costs and benefits. Next, students develop their own views and value positions on science and technological issues, before taking action. Hodson proposes the action-taking as a necessary conclusion to STSE instruction. He notes, "It is almost always much easier to proclaim that one cares about an issue than to do something about it!" The students who have the 
opportunity to act on an issue will have the benefit of a deep, personal understanding and investment in learning.

STSE education was first introduced in the 1970s, after social movements of the 1960's and 1970s called for a change in science to include society, politics and the idea of responsible citizenship (Rose ${ }^{47}$, 1994). As citizens, we face issues involving science, including those pertaining to the environment, health and medicine, and world population, and STSE instruction provides students with the tools to take on the responsibility of these problems (Rubba $\left.^{50}, 1987\right)$. STSE education recognizes that science must serve the needs of everyday people and not only political leaders and corporate executives (Soloman ${ }^{54}$, 1993). It also realizes that we need citizens that are not only capable of understanding traditional scientific knowledge, but are also able to participate in the creation of public policies (Heath $\left.{ }^{24}, 1993\right)$. The issue-oriented instruction that is used can result in a strong commitment to problem solving, higher level thinking about important concepts and a true investment in the resolution of these issues. Without an STSE education approach, the science students receive may be disjointed and fragmented, with an over-emphasis on content and lack of relevance to students' interests (Duggan and Gott ${ }^{17}, 2002$ ).

The STSE educational movement is a way to encourage students to use science to create a better future, through a more sophisticated understanding of science and how it relates to everyday life (Fourez $\left.{ }^{20}, 1995\right)$. It attempts to bring the teaching of science closer to the needs of the student, as a member of a society that has become more technologically developed (Solbes and Vilches ${ }^{53}$,1997). STSE education aims to help students make sense of everyday experience through an increased knowledge of science (Aikenhead $\left.{ }^{2}, 1994\right)$. It provides students with ideas on how to organize and comprehend the large amount of scientific and technological information that we receive through education and the media (Duggan and Gott $\left.^{17}, 2002\right)$.

The instructional strategies behind STSE education include activities that are studentoriented, whereby students integrate their personal understandings of social and natural environments (Aikenhead ${ }^{1}, 1994$ ). STSE education requires a wider variety of teaching methods, including discussion, problem-solving, debates, decision-making and use of media and community resources - any activities that are conducive to bringing out "citizenship behaviour" $\left(\right.$ Heath $\left.^{24}, 1992\right)$.

STSE education content includes a thorough exploration of social issues as they relate to science, giving students an understanding of the scientist's and engineer's responsibility (Aikenhead $^{2}$, 1994). STSE educational content includes an understanding of issues within the science $\&$ engineering community, such as philosophical differences, history and interpersonal dynamics within the community (Aikenhead ${ }^{1}$, 1994). STSE education also discusses how and why scientific knowledge is developed (Tsai $\left.{ }^{64}, 1999\right)$. Supporters believe it is important to have an understanding of the history of science, engineering and technology, so that we can understand the context of an invention and its intended purpose (Fourez ${ }^{20}$, 1995). STSE education provides information about the relationship between scientists and greater society, and how this affects the progress of science (Solbes and Vilches ${ }^{53}$, 1997). It helps us understand that science does not happen without human influence, and that the opinions and background of each scientist or engineer does affect their work (Soloman ${ }^{55}$, 1994). 
Some teachers fear that more time spent on STSE education will diminish preparation for university science courses (Aikenhead ${ }^{1}$, 1994, Duggan and Gott ${ }^{17}, 2002$, Soloman ${ }^{54}$, 1993). However, it has been found that success in university relies on attributes such as good study habits, motivation and creativity - and not the content of high school science courses. In fact, it has even been found that taking high school science classes did not affect success at university. This leads us to believe that the ability to interact with science through STSE education, such as taking action and communicating with others, may be just as important as having detailed knowledge of scientific concepts (Duggan and Gott ${ }^{17}, 2002$ ).

STSE education has proven to provide many advantages to students. A synthesis of research, conducted by Aikenhead ${ }^{2}$ (1994) made the following conclusions:

1) Students in STSE education classes improve their understanding of social issues and the interactions between science, technology and society

2) Students in STSE education classes improve their attitudes towards science and learning

3) Students make gains in applying science to everyday situations, critical thinking, creative thinking and decision making

4) Achievement at the next level (for example, university) will not be compromised.

Solbes and Vilches ${ }^{53}$ (1997) also found that students who had been taught using an STSE education-oriented approach had a more realistic conception of science.

STSE education is important because it provides a way to inform citizens on making decisions and participating in policy formation. It gives people independence and understanding, so we can all communicate about science and technology and have the confidence to take action. Taking action on an issue of importance to a particular student or group of students is an important part of the STSE education approach. According to a study by Wiesenmayer and Rubba ${ }^{67}$ (1999), students who received STSE oriented instruction significantly increased the number of citizenship actions they took. These students were exposed to teaching that provided students with the skills to take action and actually practice taking action in class.

From the perspective of career success, in a 1993 employer survey, the majority of individuals who participated reported that their engineering employees lacked the following skills (Armstrong and Leder $^{3}, 1995$ )

1. Cross-disciplinary knowledge

2. Practice Skills

3. Management Skills

4. Personal and Interpersonal skills

Due to the nature of STSE education, and its inclusion of group work, interaction and interdisciplinary knowledge, these are some of the skills that can be acquired through an STSE educational approach. Parents also encouraged the use of STSE education in the classroom, as a study by Cross and Yager ${ }^{14}$ (1998) demonstrated. The parents in the study wanted their children to have the ability to make judgments about whether technological impacts were socially acceptable so their children had a better understanding of the development of scientific knowledge.

The benefits of an STSE educational perspective are clear, but how does this approach address the female's issues in moral development, gender roles and gender stereotypes? This is explored through an in-depth look at STSE education and its benefits to female learners. 
To increase the number of women in science and engineering, we must see a shift in the curriculum content and teaching methods in those fields (Rosser $\left.{ }^{48}, 1993\right)$. Interest is a precursor to learning, and being interested in engineering and the physical sciences depends on the context in which it's presented, student and teacher interactions and the activities students engage in while learning (Hoffmann $\left.{ }^{28}, 2002\right)$. We will now examine how, specifically, STSE as an instructional technique and as curricular content can be of benefit to the female learner. Through the interviews, it was determined that the female subjects were very interested in the human side of engineering and an "STSE" approach, as demonstrated by the comments provided below.

The Winning Women research project in Scotland proposed some reasons for women leaving science and engineering programs in universities and colleges (Cronin and Roger ${ }^{13}, 1998$ ):

- The masculinity behind science $\&$ engineering, concerned with things rather than people

- Isolated content

- Negative attitude of peers

- Narrow course content

- Lack of opportunities for cooperative learning

- Emphasis on individual competition

- Inadequate counseling about related careers

- Concerns about combining career with family

Seymour $^{51}$ (1995) also suggested that competition, narrow content, lack of application and lack of interactive learning affect a female's interest in science. Many of these reasons can be addressed by STSE education - for example, isolated and narrow course content can be combated with the interdisciplinary and context-rich nature of STSE education.

The standard view in science education is that we want to induce students into the culture of scientists and research - however, this is a distant and often irrelevant community for most elementary, high school and even many university students (Brickhouse, Lowery and Schultz $\left.{ }^{8}, 1999\right)$. Some facets of science and engineering can also be discouraging, such as those that have been destructive to people and the environment (Rosser $\left.{ }^{49}, 2003\right)$. Educators need to help females understand how engineering can address social issues (Thom ${ }^{61}, 2001$ ), and find ways to personalize science and demonstrate its applicability to each and every individual, so females can recognize the relationships, decision-making and compromising skills required in making socio-scientific decisions. On the premise of difference feminism, girls might be interested in science that connects to human bodies, children, and women's traditional responsibilities (Howes $\left.{ }^{29}, 2002\right)$. STSE education is one pedagogical idea that can be applied to issues of humankind and society. This is particularly important for females, where traditional science education practice is thought to be conducive to the marginalization of females (Tsai $\left.{ }^{65}, 2000\right)$, as noted in our exploration of women and STEM.

When physics is contextualized so as to emphasize the social and applied importance of the work, more girls take physics and enjoy it - and additional research indicates that girls who enjoy physics the most are able to relate it to social issues and their personal views on science and society (Armstrong and Leder ${ }^{3}, 1995$, Labudde et $\mathrm{al}^{37}, 2000$, Soloman $^{55}, 1994$ ). Science should be context-driven, starting with student interests and the fascinating stories behind women in science and engineering (Kenway and Gough $\left.{ }^{33}, 1998\right)$. It is generally recognized 
that female students prefer to discuss social issues during learning (Tsai $\left.{ }^{65}, 2000\right)$ and STSE education brings social issues to science studies. Discussing the practical side of science and engineering, and how useful they have been in improving people's lives is of the utmost importance - in fact, most girls who choose to study science describe it in the context of a social or environmental issue (Rosser $\left.{ }^{48}, 1993\right)$. Many scientists and engineers working in their field believe that making course curriculum more socially relevant would interest more females, based on their personal learning experiences (Armstrong and Leder ${ }^{3}$, 1995).

In the interviews, all of the subjects echoed these sentiments surrounding the importance of applicable topics, impact on society and practical importance within the curriculum and their future aspirations:

"I know that I'm not going to be one of those technical engineers. I plan to continue with business, and probably working with an NGO, or doing development work-somewhere I can use my expertise to make a difference."

"In engineering, I have incredibly intelligent male friends who love looking at the abstract, and they don't need a context, they just get it. I need that, that context, and it took some getting use to in engineering."

"In grade 12 physics, I did a project on the physics of Barbie, and how she couldn't be a real woman. That was a good and bad experience. I really enjoyed doing that project...because it translated physics to an every day object. But my teacher hated it and I did not do well."

"I've always really liked biology...we'd learn about our body systems, and then I'd go to lunch and think "wow, this is actually happening!"

"One of my favorite classes was science and society...that was one of the most interesting things. You got to discuss current and contemporary issues, like the loss of biodiversity, and invitro fertilization."

"The courses that make the most sense to me were the ones that had real-world examples, like mechanical design - how you design things for people, for the environment - there were so many real-life examples.

STSE education can provide a connected way of knowing, similar to the theory of moral development described by Carol Gilligan, rather than the typical isolated nature of science and engineering $\left(\mathrm{Jacobs}^{30}, 1992\right)$. Girls are more likely to be interested in science and engineering when problem-solving and the consideration of human needs and desires is required to understand the context of the problem, unlike males who are comfortable solving a problem in isolation (Armstrong and Leder $\left.{ }^{3}, 1995\right)$. One study that looked at physics curriculum found that girls were more interested in physics when it related to humankind, social involvement and medicine. Males did not suffer from learning physics in this context essentially, what is interesting for girls in physics is also interesting for boys, but not necessarily vice versa (Hoffmann $\left.{ }^{28}, 2002\right)$. Females generally feel more comfortable solving a problem in a broader world view, or if they can compare the problem to another field of study, such as medicine, where boys starting points are often quite abstract (Stadler, Duit and Benke $^{57}, 2000$ ). By teaching students through an STSE education perspective, we provide the opportunity for students to explore traditional science content through a human and societyrelated problem. 
The interview subjects also expressed that females have an interest in helping others, and making a difference to other individuals, through their work as an engineer:

"I really wanted to go through life, and do something, make a difference somewhere. To make a difference, to some people, even if it's small."

"I think with other professions, like medicine - you have that sense that you're going to care for patients. You'll have a need to make them feel better. With engineering, the way it's marketed, it's very math, science, numbers, research this, and closed off. I think girls are more into professions that allow you to help someone directly."

"I think some girls who are strong in science and math go towards biology, or human sciences...they feel that engineering is really technical, and that you don't get to interact with people and help people."

"You do help people in engineering, it's not just being in a lab. Whether it's the health profession, or helping people overseas."

"I really like learning about companies and research that my professors were doing that helps people. I spoke with a professor about finding a job working with children, and they pointed me to children's hospitals, to work with children with special needs. I enjoyed learning about something that has a big impact on people, rather than behind-the-scenes number crunching."

The examples from all the subjects interviewed, both pertaining to their interest in engineering, society and real-life applications, as well as being involved in a profession where you can help others, were plentiful. All of the subjects felt very strongly that this was an important part of their education and their future, and that many other females felt the same way. A common theme that ran through the interviews, in regards to their curriculum, was that there was not enough emphasis on engineering \& society and the intersection between technology and helping others.

A typical STSE instructional strategy includes active and cooperative learning, which are highly regarded as being beneficial to females (Brickhouse, Lowery and Schultz ${ }^{8}, 1999$, Thom $^{62}$, 2002). Literature supports the idea that females are typically more collaborative, less aggressive and more moral than males, and if this is the case, females will benefit from a science education that de-emphasizes competition and promotes a collaborative working environment (Tolley $\left.{ }^{63}, 2003\right)$. Thom ${ }^{61}$ (2001) recommends including community members and parents in STSE education, so students learn from those outside the school and recognize the importance of the collaboration and opinions of several people when considering socioscientific issues.

As STSE "personalizes" science, it allows females to focus on ideas and issues they care about, and provides an outlet for females to examine the relationships between various issue stakeholder groups. As suggested by $\operatorname{Hodson}^{26}(1998)$, we often treat science as complex, abstract concepts that will later, if at all, be applied - and if we can give students the opportunity to engage in their own scientific interests, taking account of their own beliefs, experiences and ideas, we can create a more relevant science education. It's often argued that girls need to explore context and interrelationships when encountering new topics in math 
and science, to demonstrate the significance of the context (Bevan $\left.{ }^{7}, 2001\right)$. Girls tend to be most interested in topics in math and science that relate to people and their predicaments, and STSE education provides many opportunities to consider science-related issues that affect people's well-being and questions the responsibility of groups and individuals (Soloman ${ }^{55}$, 1994). STSE education can help us communicate with others about science, and gives us the know-how and confidence to defend our viewpoints and take action (Fourez $\left.{ }^{20}, 1995\right)$. With STSE education, science teaching becomes a human place, showing history, related to our decisions, culture and society.

A study conducted by Tsai ${ }^{64}$ in 1999 looked at a group of female grade 10 students in different science classes. One class used a traditional science education approach, following the text book and using traditional labs and lectures, in comparison with a class that used an STSE education perspective through content that related science to society, as well as thorough changes in the teacher's instructional approach that included student-centered learning, cooperative learning, issues-based debates and discussion. The author found that those taught in the STSE-oriented approach had a significantly increased ability to look at scientific concepts from different perspectives and recognizing the importance of cultural ideas in science. Tsai ${ }^{65}$ (2000) also found that the STSE education method provided the female students with a greater and richer understanding of scientific concepts.

While some believe STSE education is only effective at the secondary level, we must recognize that it is of the utmost importance that females become interested in science at a very young age. STSE education can and should be explored in the elementary grades, as demonstrated by Pedretti ${ }^{42}$ (1997) who found that a grade $3 \& 4$ class, engaged in STSE education was able to form opinions, make decisions and take action in respect to a socioscientific issue. This is very significant in the recognition of the importance of providing females with meaningful experiences in science, engineering and mathematics at a young age, and provides us with the evidence that we can engage females in STSE education at a very young age.

STSE education has the potential to provide the relational context in physics, math and engineering that females need to take interest and pursue an academic program and career in one of these fields. Implementation issues remain, which are examined in the next section.

\section{Implementing STSE Education for Females}

When implementing STSE education for females, we cannot employ STSE teaching and curriculum at its face value - we must actively consider the reasons why females do not traditionally chose physics, engineering and mathematics and ensure we provide significant focus on people, relationships, how these are affected by science. While the exploration of socio-scientific issues is normally conducive to this, we must actively ensure that our STSE curriculum is rich with the connections between people and science - and furthermore, the relationships between the individuals making decisions on science and technology.

Like any change, implementing STSE curriculum and paying particular attention to the encouragement of female students requires professional development programs for teachers, designed to show them how to relate an STSE education approach to the science and math curriculum, as well as how to implement teaching tactics designed to encourage girls and continually examine their own behaviour and gender biases (Thom $\left.{ }^{62}, 2002\right)$. It is also important to note that the gender of a teacher can affect opinions, biases and even ideas on 
STSE education and this should be taken into account when training teachers (Zoller and Ben-Chaim $^{72}$, 1994). The greatest barriers to STSE education are the traditional textbook and other teaching methods that teachers may feel more comfortable with, as well as the fact that many science teachers in the schools are trained in pure science, and may not feel comfortable facilitating a class that discusses technology, applications of science and issues (Yager and Lutz ${ }^{71}, 1995$ ). These are all factors that should be accounted for when developing training programs for new and practicing teachers.

\section{Other Notable Strategies}

Beyond the use of an STSE orientation, other strategies can be used that highlight a female's potential interest in making human and personal connections through science. A sense of openness and supportiveness in the school is incredibly important, so that females will know they have individuals from outside their family who support them (The Condition of Education $\left.1997^{60}, 1998\right)$. Sincere praise and the sharing of experiences and advice are thought to be good strategies when encouraging girls to consider studying science, engineering or mathematics (Labudde et $\mathrm{al}^{37}, 2000$ ).

Mentorship and positive role models who have succeeded in science and engineering are seen as a good option to encourage girls (Rosser ${ }^{48}, 1993$, Thom $\left.^{61}, 2001\right)$, highlighting the idea of relationships as a major influence in female identity development. Women-only science classes and clubs have been developed, to provide female students with a unique learning atmosphere (Stage et $\mathrm{al}^{56}, 1985$ ).

As STSE education encourages sharing knowledge of the history of science and scientists, this can also be used as a strategy to share the stories of female scientists and engineers. There are many interesting stories of pioneering female engineers, from Kate Gleason, one of the first women to study engineering who went on to become the first female president of a bank, to Lillian Gilbreth, a mother of 12 who owned and operated a management consulting company and eventually became a faculty member at Purdue university (Lebold and Lebold $^{38}$, 1998).

In the United States, where the retention of women in engineering and science is a major issue with up to $40 \%$ of females leaving these academic programs after years 1 or 2 , first year orientation courses that provide students with information on related careers and options have received a very positive response from students (Atkin, Green and McLaughlin ${ }^{4}$, 2002).

When encouraging females to consider engineering and the physical sciences, we can also explore the idea that when women are in science and engineering professions, there is a "female style" (Barinaga ${ }^{5}$, 1993). This female style is thought to include a collaborative laboratory atmosphere, with less competition and more room to grow at one's own pace. Barinaga $^{5}$ (1993) also felt that conflict resolution was different within this "female style", where female science and engineering leaders are more likely to listen to different opinions and make efforts to come to a middle ground, and that more views and opinions can only mean better science. While some feel that identifying a female style of science will cause some people in the science and engineering communities to feel it is not as good, it can be a valuable exercise in demonstrating that there are many ways to approach scientific and engineering-related activities and that females do have the ability to make significant contributions. 
Today, despite the progress that has been made, women must still conform to the cultural norms of science, mathematics and engineering that were created in a time where only men dominated the progress in these fields. To make a significant difference in the way in which women are involved in these fields, we must shift the way we view science and what is important in science, and this paper suggests that a stronger STSE education focus is one way to achieve this, both in high school science and math as a recruitment tool for engineering, and within engineering curriculum as a method of keeping our female students engaged in their studies.

One of the difficulties we face is that much of the gender research presented in this paper does not account for the diversity within each gender group (Brickhouse, Lowery and Schultz $\left.{ }^{8}, 1999\right)$ Gender is complex, and boys and girls do not necessarily fit into neat categories. Students are also influenced not only by their gender but also their race, class and other factors, and to truly understand how to encourage more girls to consider science, engineering and mathematics we need to understand how they construct their identity as a whole. We must also consider that when conducting research about gender, the experience and sex of the researcher, the content of the study and the subjects all affect results (Eisenberg, Martin and Fabes ${ }^{19}$, 1996).

Through qualitative interview data, common themes that the female interviewees discussed have been raised in the context of our ongoing struggles to recruit women to the engineering field. The data has also indicated that there is much work to be done in the stereotypes and student experience faced by our female engineering students. While these students are persisting, the issues they raise may negatively affect the persistence of other students, and the attitudes of our female students towards the field of engineering.

Along with themes that explain our ongoing struggles, also demonstrated through this paper are the interests of our female students and possibilities for further curriculum reform. While STSE is being delivered, to a varying extent, at the high school and university level, there are opportunities to further contextualize and make meaning of our entire engineering and preengineering curricula. While both males and females seem to respond well to STSE education, it is females who often lose interest in science, engineering and mathematics when these topics are omitted, hence the significance in providing this educational strategy to encourage females. Through the closer examination of the human side of science, using an issues-based STSE education approach, we can provide all students with the benefits of a more meaningful science and engineering experience, and provide females with the relational context they need to pursue these academic disciplines and careers. Further research, potentially with females who chose not to pursue engineering, will help support the need for new approaches in both recruitment and curriculum.

Bibliography

1. Aikenhead, G. (1994). What is STS Teaching? In J. Solomon and G. Aikenhead (Eds.), STS education: International perspectives on reform (pp. 47-59). New York: Teachers College Press. 
2. Aikenhead, G. (1994). Consequences to Learning Science through STS: A Research Perspective. In J. Solomon and G. Aikenhead (Eds.), STS education: International perspectives on reform (pp. 169-186). New York: Teachers College Press.

3. Armstrong, J. and Leder, G. (1995). Engineering education: how to design a genderinclusive curriculum. 1995 International Congress of Engineering Deans and Industry Leaders. Monash University, 3-6 July 1995, pp. 292-297.

4. Atkin, A.M., Green, R., and McLaughlin, L. (2002). Patching the Leaky Pipeline: Keeping First-Year College Women Interested in Science. Journal of College Science Teaching, 32, 102-108.

5. Barinaga, M. (1993). Is there a Female Style in Science? Science, 260, 384-393.

6. Bebbington, D. (2002). Women in Science, Engineering and Technology: A Review of the Issues. Higher Education Quarterly, 56, 360-375.

7. Bevan, R. (2001). Boys, Girls and Mathematics. Mathematics in School, 30, 2-6.

8. Brickhouse, N.W., Lowery, P. and Schultz, K. (1999). What Kind of a Girl Does Science? The Construction of School Science Identities. Journal of Research in Science Teaching, 37, 441-458.

9. Byrnes, J.P. and Takahira, S. (1993). Explaining Gender Differences on SAT-Math Items. Developmental Psychology, 29, 805-810.

10. Campbell, J.R. and Beaudry, J.S. (1998). Gender Gap Linked to Differential Socialization for High-Achieving Senior Mathematics Students. The Journal of Educational Research, 91, 140-147.

11. Canadian Council of Professional Engineers. (2005). Engineering Enrolment and Degrees Awarded.

12. Cordova-Wenthing, R.M. and Camacho, C. (2006). Women Engineers: Factors and Obstacles Related to the Pursuit of a Degree in Engineering. Proceedings of the 2006 ASEE Annual Conference \& Exposition: Excellent in Education, Chicago, Il., USA, 18-21 June.

13. Cronin, C. and Roger, A. (1998). Theorizing Progress: Women in Science, Engineering and Technology in Higher Education. Journal of Research in Science Teaching, 36, 637-661.

14. Cross, R.T. and Yager, R.E. (1998). Parents, Social Responsibility and Science, Technology and Society (STS): A Rationale for Reform. Research in Science and Technological Education, 16, 5-18.

15. Desouza, J.M.S. and Czerniak, C.M. (2002). Social Behaviours and Gender Differences Among Preschoolers: Implications for Science Activities. Journal of Research in Childhood Education, 16, 175-188. 
16. Dimitrov, D.M. (1999). Gender Differences in Science Achievement: Differential Effect of Ability, Response Format, and Strands of Learning Outcomes. School Science and Mathematics, 99, 445-450.

17. Duggan, S and Gott, R. (2002). What sort of science education do we really need? International Journal of Science Education, 24, 661-679.

18. Eccles, J.S. and Jacobs, J.E. (1986). Social Forces Shape Math Attitudes and Performance. Signs: Journal of Women in Culture and Society, 11, 367-80.

Friedman, E.G. and Marshall, J.D. (2004). Issues of Gender. New York: Pearson Education Inc.

19. Eisenberg, N., Martin, C.L. and Fabes, R.A. (1996). Gender development and gender effects. In D.C. Berliner \& R.C. Calfee (Eds.), Handbook of Educational Psychology (pp. 358-396). New York: Macmillan.

20. Fourez, G. (1995). The science, technologies and society (STS) movement and the teaching of science. Prospects, 25, 27-40.

21. Fox, M.F. and Colatrella, C. (2006). Participation, Performance and Advancement of Women in Academic Science and Engineering: What is at Issue and Why. Journal of Technology Transfer, 31, 377-386.

22. Gilligan, C. (1982). In a Different Voice. Cambridge: Harvard University Press.

23. Golombok, S. and Fivush, R. (1994). Gender Development. Cambridge: Cambridge University Press.

24. Heath, P.A. (1992). Organizing for STS Teaching and Learning: The Doing of STS. Theory Intro Practice, 16, 52-58.

25. Hekman, S.J. (1995). Moral Voices, Moral Selves. Pennsylvania: Pennsylvania State University Press.

26. Hodson, D. (1998). Teaching and Learning Science: towards a Personalized Approach. Philadelphia: Open University Press.

27. Hodson, D. (2003). Time for action: science education for an alternative future. International Journal of Science Education, 25, 645-670.

28. Hoffmann, L. (2002). Promoting Girls' Interest and Achievement in Physics Classes for Beginners. Learning and Instruction, 12, 447-65.

29. Howes, E.V. (2002). Connecting Girls and Science: Constructivism, Feminism and Science Education Reform. New York: Columbia University Teachers College Press.

30. Jacobs, J. (1992) Women's Learning Styles and the teaching of Mathematics. Math \& Science For Girls: A Symposium, 43-55. 
31. Jones, C.E. and Watt, J.D. (2001). Moral Orientation and Psychosocial Development: Gender and Class-Standing Differences. NASPA Journal, 39, 1-13.

32. Karp, K. and Shakeshaft, C. (1997). Restructuring Schools To Be Math Friendly to Females. NASSP Bulletin, 81, 84-93.

33. Kenway, J. and Gough, A. (1998) Gender and science education in schools: a review "with attitude". Studies in Science Education, 31, 1-30.

34. Kohlberg, L, Levine, C. and Hewer, A. (1983). Moral Stages: A Current Formulation and a Response to Critics. Switzerland: Karger.

35. Kohlstedt, S.G. (ed) (1999). History of Women in the Sciences. Chicago: The University of Chicago Press.

36. Langford, P.E. (1995). Approaches to the Development of Moral Reasoning. East Sussex: Lawrence Erlbaum Associates, Ltd., Publishers.

37. Labudde, P. et al. (2000). Girls and Physics: Teaching and Learning Strategies Tested by Classroom Interventions in Grade 11. International Journal of Science Education, 22, 143157.

38. Lebold, W.K. and Lebold, D.J. (1998). Women Engineers: A Historical Perspective. ASEE Prism, 7, 30-2.

39. Linn, M.C. and Hyde, J.S. (1997) Trends in Cognitive and Psychosocial Gender Differences. In Gauvain. M. and Cole, M. (Eds.) Readings on the development of children $\left(2^{\text {nd }}\right.$ ed.) (pp. 240-248). New York: W.H. Freeman.

40. McPhedran, L. (2003). The Women's Institute: The Origins of Science Education for Women in Rural Ontario. In Hodson, D. (Ed.) OISE papers in STSE education, volume 4. Toronto: University of Toronto Press.

41. O'Keefe, E.S.C. and Hyde, J.S. (1983). The Development of Occupational Sex-Role Stereotypes: The Effects of Gender Stability and Age. Sex Roles, 9, 481-493.

42. Pedretti, E. (1997). Septic tank crisis: a case study of science, technology and society education in an elementary school. International Journal of Science Education, 19, 12111230.

43. Pedretti, E. (1999). Decision Making and STS Education: Exploring Scientific Knowledge and Social Responsibility in Schools and Science Centers Through an IssuesBased Approach. School Science and Mathematics, 99, 174-181.

44. Ramirez, F.O. and Wotipka, C.M. (2001). Slowly but Surely? The Global Expansion of Women's Participation in Science and Engineering Fields of Study, 1972-1992. Sociology of Education, 74, 231-251.

45. Reis, S.M. and Park, S. (2001). Gender Differences in High-Achieving Students in Math and Science. Journal for the Education of the Gifted, 25, 52-73. 
46. Robinson, C.C. and Morris, J.T. (1986). The Gender-Stereotyped Nature of Christmas Toys Received by 36-, 48-, and 60-Month-Old Children: A Comparison Between Nonrequested vs. Requested Toys. Sex Roles, 15, 21-32.

47. Rose, H. (1994). The Two-Way Street: Reforming Science Education and Transforming Masculine Science. In J. Solomon and G. Aikenhead (Eds.), STS education: International perspectives on reform (pp. 155-166). New York: Teachers College Press.

48.Rosser, S.V. (1993). Female friendly science: including women in curricular content and pedagogy in science. The Journal of General Education 42, 191-220.

49. Rosser, S.V. (2003). Attracting and retaining women in science and engineering. Academe. 89, 24-29.

50. Rubba, P.A. (1987). Perspectives on science-technology-society instruction. School Science and Mathematics, 87, 181-186.

51. Seymour, E. (1995). The Loss of Women from Science, Mathematics, and Engineering Undergraduate Majors: An Explanatory Account. Science Education, 79, 437-473.

52. Simon. M.K. (2000). The Evolving Role of Women in Mathematics. Mathematics Teacher, 93, 782-786.

53. Solbes, J. and Vilches, A. (1997). STS interactions and the teaching of physics and chemistry. Science Education, 81, 377-386.

54. Solomon, J. (1993). What and why is STS? In Solomon, J., Teaching Science, Technology and Society. Philadelphia: Open University Press.

55. Soloman, J. (1994). Learning STS and Judgments in the Classroom: Do Boys and Girls Differ? In J. Solomon and G. Aikenhead (Eds.), STS education: International perspectives on reform (pp. 141-154). New York: Teachers College Press.

56. Stage, E. et al.. (1985). Increasing the Participation and Achievement of Girls and Women in Mathematics, Science and Engineering. In Klein, S. (Ed). Handbook for Achieving Sex Equity through Education (pp 237-268). Baltimore: Johns Hopkins.

57. Stadler, H., Duit, R. and Benke, G. (2000). Do Boys and Girls Understand Physics Differently? Physics Education, 35, 417-22.

58. Tatar, M. and Emmanuel, G. (2001). Teachers' Perceptions of Their Students' Gender Roles. The Journal of Educational Research, 94, 215-224.

59. Taylor, F. (2003). Content Analysis and Gender Stereotypes in Children's Books. Teaching Sociology, 31, 300-311.

60. The Condition of Education 1997. (1998) Girls Math/Science Education. The Education Digest, 63, 42-48. 
61. Thom, M. (2001). Young Women's Progress in Science and Technology Studies:

Overcoming Remaining Barriers. NASSP Bulletin, 85, 6-19.

62. Thom, M. (2002). Girls in Science and Technology: What's New, What's Next? The Education Digest, 67, 17-24.

63. Tolley, K. (2003). The Science education of American Girls: a historical perspective. New York: Routledge Falmer.

64. Tsai, C. (1999). The progression toward constructivist epistemological views of science: a case study of the STS instruction of Taiwanese high school female students. International Journal of Science Education, 21, 1201-22.

65. Tsai, C. (2000). The effects of STS-oriented instruction on female tenth graders' cognitive structure outcomes and the role of student scientific epistemological beliefs. International Journal of Science Education. 22, 1099-115.

66. West, J.D. and Bursor, D.E. (1984). Gilligan and Kohlberg: Gender Issue in Moral Development. Journal of Humanistic Education and Development, 22, 134-142.

67. Wiesenmayer, R.L. and Rubba, P.A. (1999). The Effects of STS Issue Investigation and Action Instruction versus Traditional Life Science Instruction on Seventh Grade Students' Citizenship Behaviours. Journal of Science Education and Technology, 8, 137-144.

68. Witt, S. D. (1997). Parental Influence on Children's Socialization to Gender Roles. Adolescence, 32, 253-259.

69. Witt, S.D. (2000). The Influence of Television on Children's Gender Role Socialization. Childhood Education, 76, 322-324.

70. Witt, S.D. (2000). The Influence of Peers on Children's Socialization to Gender Roles. Early Child Development and Care, 162, 1-7.

71. Yager, R. E. and Lutz, M. V. (1995). STS to Enhance Total Curriculum. School Science and Mathematics, 95, 28-35.

72. Zoller, U. and Ben-Chaim, D. (1994). High school students' and teachers' STS outlook profiles. Are there gender differences? International Journal of Mathematical Education in Science and Technology, 25, 423-430. 